\title{
CLINICAL, ENDOSCOPIC AND HISTOPATHOLOGICAL PROFILES OF PARASITIC DUODENITIS CASES DIAGNOSED BY UPPER DIGESTIVE ENDOSCOPY
}

\author{
Reinaldo Benevides dos SANTOS, Luciano Espinheira FONSECA Jr., \\ Andrea Tosta de Azevedo SANTANA, Carolina Alves Costa SILVA and Jorge Carvalho GUEDES
}

\begin{abstract}
Context - Intestinal parasites induce detectable histopathological changes, which have been studied in groups with known diagnosis of parasitic disease. There is no available study with a larger base without previous diagnosis. Objective - To describe clinical and histopathological findings of parasitosis diagnosed by endoscopic biopsy in patients submitted to upper digestive endoscopy. Methods - Recorded biopsies archive at "Complexo Hospitalar Professor Edgar Santos", a general teaching Hospital in the state of Bahia, Northeast Brazil, from January 1995 to January 2009, were reviewed. One thousand ten duodenal biopsy reports were found. Reports positive for parasites had their specimens reviewed and photographed. All blocks of biopsy selected as case were retrieved and reviewed by an experienced pathologist. Clinical, laboratorial and endoscopic data were collected. Results - Eleven biopsies showed parasites, including cases of Cryptosporidium sp. and Strongyloides stercoralis. Vomiting (91\%), abdominal pain (78\%), diarrhea $(78 \%)$ and weight loss $(78 \%)$ were usual symptoms. Seventy-five percent had duodenal mucosa changes on endoscopy, while $25 \%$ have no changes. Anemia and low serum albumin were important laboratorial data. HIV infection association was observed. Villus atrophy and reactive epithelium were usual in Strongyloides cases. Conclusions - No endoscopic or histopathologic finding was pathognomonic. One percent of duodenal endoscopic biopsies showed parasites.
\end{abstract}

HEADINGS - Intestinal diseases, parasitic. Duodenitis. Biopsy. Endoscopy, gastrointestinal.

\section{INTRODUCTION}

Parasitic duodenitis is a relevant cause of morbidity, especially in developing countries. Moreover, parasitic diseases have acquired highlights in the context of immunosuppressive diseases, especially after the emergence of HIV pandemic and propagation of immunomodulation therapies. In such cases, intestinal parasitosis can promote severe disease and lead to death.

Few papers study duodenum specifically parasitic infections. Epidemiological data are poor and, in most cases, all gastroenteritis are displayed together. Thereby, the relevance of works outlining the parasitic duodenitis profile is clear.

The main clinical manifestations are diarrhea, vomiting, nausea, abdominal pain and weight loss. Some studies mention the appearance of intestinal blockage, fever and evolution to sepsis ${ }^{(2,4,5,8,9)}$.
The most common endoscopic findings are mucosal edema, erythema, friability, white villi, erosion and pseudopolyps. In $S$. stercoralis infection, it was also observed presence of protein-losing enteropathy ${ }^{(2,4,8)}$.

Histopathological findings showed edema and infiltration of the lamina propria by lymphocites and plasmocites, shortened or absent villus, cryptitis and crypt hyperplasia, epithelial layer infiltration by numerous intra-epithelial lymphocites and antigen-presenting cells and the presence of lymphagectasia ${ }^{(2,4,5,8)}$.

This paper aims to set a profile of the parasitic duodenitis diagnosed by upper digestive endoscopy among patients of "Complexo Hospitalar Professor Edgar Santos" (HUPES), a general teaching Hospital in the state of Bahia, Northeast Brazil, establishing the characteristics of affected patients, the main signs and symptoms and histological findings. It is a retrospective and descriptive study of a group of cases, allowing a preliminary approach to this subject. 


\section{METHODS}

Recorded biopsies archived at HUPES, from January 1995 to January 2009 were reviewed. A total of 1010 biopsy reports from duodenum were reviewed in search of positivity for parasites. Then the positive cases were selected according to the description of the presence of parasites, either as eggs or larvae in any portion of the duodenum and others etiologies were excluded. Two cases of mycobacteria and a case of Whipple's disease were found and excluded, limiting the cases to protozoa and helminths.

After reviewing the biopsy records, clinical and laboratory data were collected from medical records of selected patients. Clinical, laboratorial and endoscopic data were extracted from reports closer to duodenal biopsy made before the beginning of antiparasitic therapy.

All blocks of biopsy selected as case were retrieved and reviewed by an experienced pathologist, to better characterize the histopathological findings. In this review, 1 of the 12 cases was excluded because the parasite quoted in the report could not be found on a new microscopy. All specimens were stained with hematoxylin-eosin (H-E).

A database was created with the standardized collected data, from which the distributions, means and medians were calculated.

The project was approved by the Ethics and Research Committee of HUPES (Protocol number 4/2009).

\section{RESULTS}

A total of 1010 biopsy records were reviewed, representing the total number of individuals attended in HUPES from January 1995 to January 2009. Among these, 11 patients had a parasite found on their biopsies and their medical records were reviewed. Thus, parasites were found in 1\% (11/1010) of duodenal biopsies performed in that period.
Table 1 summarizes the clinical and epidemiological features of cases. Seven $(63.6 \%)$ cases of $S$. stercoralis and four (36.4\%) of Cryptosporidium sp. were diagnosed in duodenal specimens. Gender distribution showed there were six $(54.5 \%)$ men and five $(45.5 \%)$ women. The clinical profile of patients showed the ubiquous presence of vomiting $(91 \%)$. Abdominal pain (78\%), diarrhea (78\%) and weight loss $(78 \%)$ were also usual symptoms. Fever $(22 \%)$ was a less common presentation.

Table 1 also shows the requested and realized protoparasitological stool examinations (55.6\%). Four (80\%) had concordant results with duodenal biopsy specimens, while one $(20 \%)$ showed no parasites.

Eight patients presented an endoscopy records attached to the medical records. Six cases $(75 \%)$ had duodenal mucosa changes on endoscopy, while two patients $(25 \%)$ have no changes (Table 1). Some endoscopic changes were exanthema (50\% of descriptions), exudates or friability (37.5\% of descriptions) and other less common findings were mucositis, erosion or edema ( $12.5 \%$ of cases). No case had the description of ulceration.

Distribution of HIV positive patients and systemic corticosteroid use is also presented in Table 1. Five patients $(50 \%)$ were HIV positive and an equal number had no reference to HIV positivity in medical records. Considering each parasite as a distinct group, all four patients with Cryptosporidium were HIV positive, while only one had both S. stercoralis and HIV as diagnosis. However, two of the patients known to be infected by $S$. stercoralis had clues of corticosteroids therapy and one of them had diagnosis of diabetes mellitus, suggesting that an immunossupression state could be concomitant.

Tables 2 and 3 show the laboratory profile of cases with S. stercoralis and Cryptosporidium, respectively. Mean rates and medians are presented for the most interesting laboratorial findings referring to valid data of

TABLE 1. Clinical and epidemiological summary of selected cases

\begin{tabular}{|c|c|c|c|c|c|c|c|c|c|c|c|c|}
\hline \multirow{2}{*}{ Case } & \multirow{2}{*}{ Agent } & \multirow{2}{*}{$\begin{array}{c}\text { Age/ } \\
\text { gender }\end{array}$} & \multicolumn{5}{|c|}{ Symptoms } & \multicolumn{2}{|c|}{ Stool examination } & \multirow{2}{*}{$\begin{array}{l}\text { Endosc } \\
\text { changes }\end{array}$} & \multirow{2}{*}{ HIV } & \multirow{2}{*}{$\begin{array}{c}\text { Sist } \\
\text { cortic }\end{array}$} \\
\hline & & & Abd pain & Vomit & Diarrhea & $\downarrow$ Weight & Fever & Performed & Positive & & & \\
\hline 1 & Strong & $26 / F$ & + & + & - & + & - & No & $* *$ & Yes & No & Yes \\
\hline 2 & Strong & $20 / \mathrm{M}$ & + & + & + & + & - & No & $* *$ & Yes & No & No \\
\hline 3 & Strong & $53 / \mathrm{M}$ & - & - & + & - & - & Yes & Yes & Yes & No & No \\
\hline 4 & Strong & $24 / \mathrm{M}$ & + & + & + & + & - & No & $* *$ & Yes & No & Yes \\
\hline 5 & Crypt & $44 / \mathrm{F}$ & + & + & + & + & + & Yes & No & $* *$ & Yes & No \\
\hline 6 & Crypt & $42 / \mathrm{M}$ & + & + & + & - & - & Yes & Yes & No & Yes & No \\
\hline 7 & Crypt & $56 / \mathrm{F}$ & + & + & + & + & - & Yes & Yes & No & Yes & No \\
\hline 8 & Strong & $33 / \mathrm{F}$ & - & + & + & + & + & No & $* *$ & $* *$ & $* *$ & $* *$ \\
\hline 9 & Strong & $37 / \mathrm{F}$ & + & + & - & + & - & Yes & Yes & Yes & No & No \\
\hline 10 & Strong & $34 / \mathrm{M}$ & $* *$ & + & $* *$ & $* *$ & $* *$ & $* *$ & $* *$ & Yes & Yes & No \\
\hline 11 & Crypt & $33 / \mathrm{M}$ & $* *$ & + & $* *$ & $* *$ & $* *$ & $* *$ & $* *$ & $* *$ & Yes & $* *$ \\
\hline
\end{tabular}

Strong (S. stercoralis); Crypt (Cryptosporidium sp.); Abd pain (abdominal pain); Stool examination (stool sample examination); Endosc changes (endoscopic changes); Syst cortic (systemic corticosteroids using); ** (not finding data) 
TABLE 2. Laboratorial profile of $S$. stercoralis cases

\begin{tabular}{|c|c|c|c|c|c|c|c|c|}
\hline Case & Age & Total lymp & Lymp (\%) & Eosinophils (\%) & $\mathrm{Hb}$ & Albumin & Serum $\mathbf{N a}$ & Serum K \\
\hline 1 & 26 & $* *$ & 15.0 & 1.0 & 14.3 & 0.60 & 130 & 5.4 \\
\hline 2 & 20 & 2226.4 & 12.1 & 0.7 & 12.7 & 1.10 & 125 & 3.2 \\
\hline 3 & 53 & 944.3 & 13.3 & 19.3 & 10.1 & 2.00 & 130 & 5.8 \\
\hline 4 & 24 & 3000.0 & 10.7 & 1.1 & 9.1 & 0.30 & 123 & 4.0 \\
\hline 8 & 33 & $* *$ & $* *$ & $* *$ & $* *$ & $* *$ & $* *$ & $* *$ \\
\hline 9 & 37 & 1953.2 & 25.7 & 2.6 & 9.7 & 2.40 & 136 & 3.4 \\
\hline 10 & 34 & $* *$ & $* *$ & $* *$ & $* *$ & $* *$ & $* *$ & $* *$ \\
\hline Mean & 32.4 & 2031.0 & 15.4 & 4.9 & 11.2 & 1.28 & 128.8 & 4.4 \\
\hline Median & 33 & 2090.0 & 13.3 & 1.1 & 10.1 & 1.10 & 130 & 4.0 \\
\hline
\end{tabular}

Lymp. (lymphocites); $\mathrm{Hb}$ (hemoglobin); $\mathrm{Na}$ (sodium); K (potassium)

TABLE 3. Laboratorial profile of Cryptosporidium sp. cases

\begin{tabular}{|c|c|c|c|c|c|c|c|c|c|}
\hline Case & Age & Total lymp. & Lymp (\%) & Eosinophils (\%) & CD4 count & $\mathrm{Hb}$ & Albumin & Serum $\mathrm{Na}$ & Serum K \\
\hline 5 & 44 & 777.0 & 37.0 & 1.0 & $* *$ & 11 & 1.30 & 138 & 4.4 \\
\hline 6 & 42 & 600.0 & 6.2 & 0.4 & 72.0 & $* *$ & 3.54 & 124 & 2.6 \\
\hline 7 & 56 & 500.0 & 11.0 & 2.7 & 43.0 & 9.1 & 2.70 & 141 & 3.5 \\
\hline 11 & 33 & $* *$ & $* *$ & $* *$ & $* *$ & $* *$ & $* *$ & $* *$ & $* *$ \\
\hline Mean & 43.8 & 626 & 18.1 & 1.4 & 57.5 & 10.1 & 2.51 & 134.3 & 3.5 \\
\hline Median & 43 & 600 & 11 & 1 & 57.5 & 10.1 & 2.70 & 138 & 3.5 \\
\hline
\end{tabular}

TABLE 4. Histopathological findings described in S. stercoralis $(\mathrm{n}=7)$ and Cryptosporidium sp $(\mathrm{n}=4)$ duodenal biopsies revision

\begin{tabular}{lcc}
\hline Histopathological finding & S. stercoralis & Cryptosporidium \\
\hline Change on villous/crypt & $42.9 \%$ & $0 \%$ \\
Presence of crypt hyperplasia & $42.9 \%$ & $0 \%$ \\
Presence of reactive epithelium & $85.7 \%$ & $25 \%$ \\
Presence of cryptitis and crypt abscess & $42.9 \%$ & $0 \%$ \\
Presence of intra-epithelial lymphocytes & $0 \%$ & $0 \%$ \\
Presence of eosinophilic infiltrate & $57.1 \%$ & $0 \%$ \\
Presence of exulceration & $42.9 \%$ & $0 \%$ \\
Lamina propria infiltration & & $50 \%$ \\
$\quad$ Mild & $28.6 \%$ & $50 \%$ \\
$\quad$ Moderate & $14.3 \%$ & $0 \%$ \\
$\quad$ Severe & $57.1 \%$ & \\
\end{tabular}

11 cases. These patients had a general profile composed by low hemoglobin levels, depletion of serum albumin and loss of electrolytes. Eosinophilia was not a common finding. Lymphopenia was clearer in Cryptosporidium cases. Eight patients had assessable transaminases values and seven showed normal levels, while only one showed border values.

Table 4 describes the main histological findings observed during biopsy specimens review. With regard to eosinophilic infiltrate in biopsies with $S$. stercoralis, two out of seven considered patients had a severe infiltrate; one was qualified as having a moderate and another as having a mild infiltrate. Remaining patients had no significant infiltration.

Figure 1 shows histopathological changes in S. stercoralis and Cryptosporidium sp. infection cases. The usual pattern of acute inflammation and reactive epithelium deserves attention, besides ulcerations, in S. stercoralis infected individuals. These changes were not observed in cases of Cryptosporidium sp. infection. In analyzed material, this infection has not determined significant inflammation or architectural changes in duodenal mucosa. 

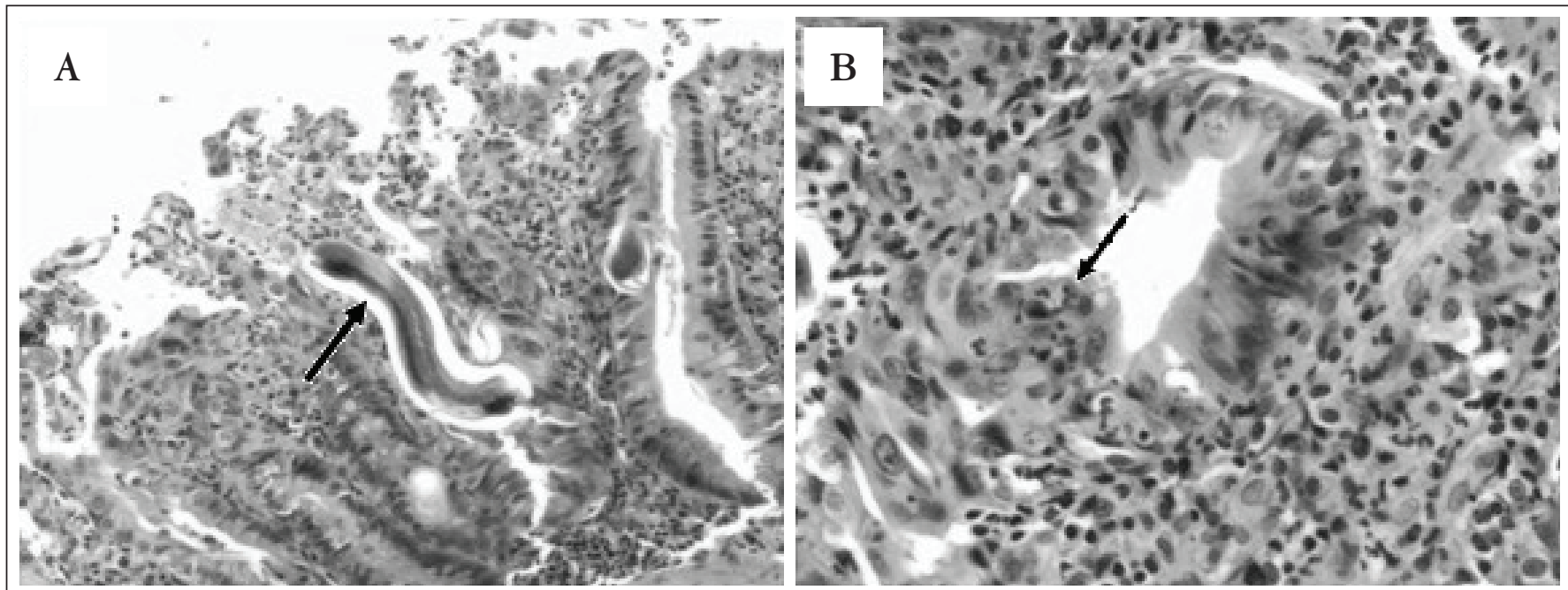

C

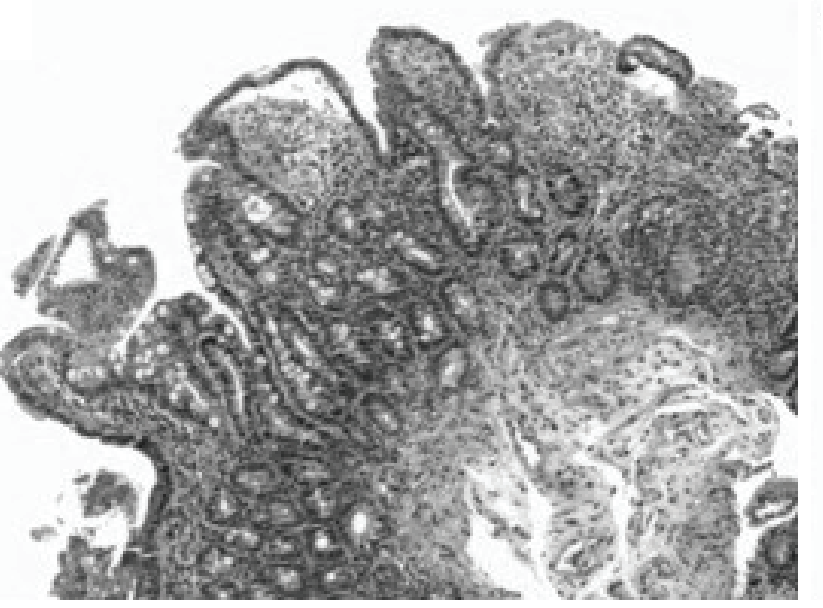

D

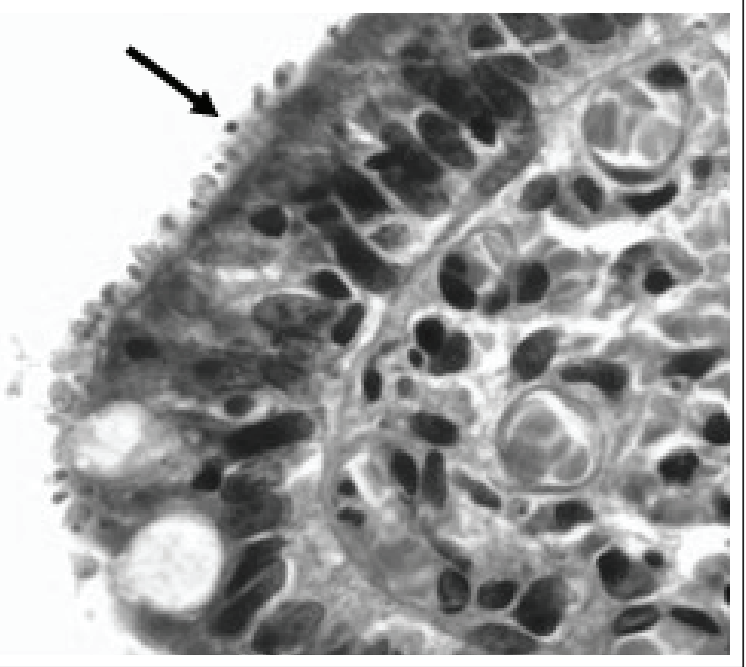

FIGURE 1. (A) Duodenal mucosa showing ulceration, reactive epithelium and rhabditoid larva of $S$. stercoralis in duodenal crypt (arrow), in patient presenting hematemesis, melena and diarrhea $<\mathrm{H}$-E staining, 200x $>$; (B) Duodenal mucosa showing reactive epithelium and intra-epithelial neutrophilic inflammation (cryptitis) in patient with hematemesis, melena and diarrhea (arrow) $<\mathrm{H}-\mathrm{E}$ staining, 400x $>$; (C) Villus pattern of duodenal mucosa preserved in a Cryptosporidium sp infected patient presenting diarrhea, vomiting, abdominal pain and AIDS diagnosis $<\mathrm{H}$-E staining, 100x $>$; (D) Preserved epithelium of duodenal mucosa without inflamation evidences and the supra-epithelial localization of protozoan (arrow) $<\mathrm{H}$-E staining, 400x $>$

\section{DISCUSSION}

Arévalo et al. ${ }^{(1)}$ performed a study where 11 cases of $S$. stercoralis were analyzed. The mean and median ages were 42 and 45 years, respectively. The male gender predominated corresponding $78 \%$ of cases. Villous atrophy was described in all cases. Severe duodenitis was reported in $36 \%$ of cases and mild duodenitis in $64 \%$. This study did not use the moderate degree classification of infiltration (moderate duodenitis). In the study performed by Macfarlane et al. ${ }^{(7)}$ just 1 of 6 cases showed crypts atrophy. One proposed explanation for this difference is the profile of patients in the care services where data were collected. According to Arévalo et al. ${ }^{(1)}$, a longer period without seeking medical care would be related to a greater degree of mucosal injury. According to data collected in HUPES, $42.9 \%$ of patients with S. stercoralis showed villous atrophy (alteration of the villous/crypt). The patients in our study are about 10 years younger when compared to the mean and median ages of Arévalo et al. ${ }^{(1)}$, but gender distribution also showed a higher proportion of men.

Weber et al. ${ }^{(13)}$, in a study envolving HIV-positive patients with diarrhea, described a mean age of 33 years and Cryptosporidium was the most common pathogen, eventually being responsible for $15.5 \%$ of cases of chronic diarrhea. It was found that most patients affected by this disease are in the age group of young adults, like data found in the study in HUPES. However, there are studies that show a greater affection in elderly ${ }^{(10)}$. 
The endoscopic examination was not more effective than the stool parasitological detection of pathogens, except in cases of cytomegalovirus and Leishmania ${ }^{(13)}$, which favors the idea of requesting a stool sample examination before performing an endoscopy in patients with abdominal complaints. This management was underappreciated according to data presented in the medical records of HUPES.

Papp et al. ${ }^{(9)}$ also demonstrated that pathogens were identified in just $13 \%$ to $18.2 \%$ of cases of acute diarrhea and $40 \%$ to $51.3 \%$ in cases of chronic diarrhea, despite of the exams. These data may show that the prevalence of enteric pathogens is underestimated in literature.

Silva et al. ${ }^{(1)}$ conducted a study in a Brazilian teaching hospital. From a group of clinically healthy individuals (a sample of 85 patients), $7.1 \%$ had positive stools examination positive for $S$. stercoralis, $7.1 \%$ for hookworm and $3.5 \%$ for Giardia lamblia. In the same study, from 100 individuals with HIV/AIDS, the parasite most commonly found was also the $S$. stercoralis $12 \%$, followed by $7 \%$ of Isospora belli and 4\% of Cryptosporidium sp. The results of this study are consistent with distribution of parasites found in HUPES. A possible explanation for the higher prevalence of $S$. stercoralis may be the presence of chronic alcoholism, which was not investigated in our study ${ }^{(11,14)}$.

Rivasi et al. ${ }^{(10)}$, in a study with nine duodenal biopsies, showed that the reactive pathological changes of duodenal mucosa, particularly the eosinophilic infiltrate of lamina propria, appear to be related to infection degree. Five of these cases had an intense eosinophilic infiltrate, two had moderate and two others had insignificant infiltrate. There is even the possibility of a false-negative histopathological exam if only the stomach is biopsied. In our study, the degree of infection was not correlated with inflammatory infiltrates, and exuberant eosinophilic infiltrates were less common. Men also appeared as the main victims. This study also demonstrated that the most affected site by $S$. stercoralis is duodenum.

Thompson et al. ${ }^{\left({ }^{12}\right)}$ studied six cases, showing that all patients with $S$. stercoralis had abdominal pain and half of them had diarrhea. Four of these patients were diagnosed by duodenal histopathology. The presence of S. stercoralis was associated with immunosuppression in four cases (corticosteroid therapy, AIDS and diabetes mellitus).

Lumadue et al. ${ }^{(6)}$ showed in their study, through analysis of gastrointestinal biopsies, that duodenum is the main location of Cryptosporidium sp. infection. Most biopsies had an increased number of lymphocytes, showing collection of lymphocytes around the base of crypts, lymphocytic expansion in the lamina propria and numerous intraepithelial lymphocytes. It was not proved the relationship between degree of infection and inflammation. Aspects such as villous atrophy (21 of 41 patients), reactive epithelium (22 of 41 patients) and apoptosis were also displayed. No aspect was pathognomonic. Unlike the study in HUPES, an inflammatory reaction with mucosa injury was more evident, which could be explained by the coexisting cytomegalovirus infection in some cases of the serie. In HUPES sample, the presence of these parasites adhered to the duodenal mucosa did not cause significant changes in the histopathological aspect of biopsies.

According to Genta et al. ${ }^{(3)}$, in a study with 18 patients presenting cryptosporidiosis and AIDS, found that 13 had normal villous architecture. These patients had a normal or moderately increased inflammatory component, consisting mainly of lymphocytes and plasma cells. Five patients had villous atrophy, which was related to more severe infections. These findings are more compatible with those found in HUPES study, showing a trend toward preservation of duodenal epithelium without an important inflammatory infiltrate in lamina propria, consistent with surface characteristic of infection by Cryptosporidium sp.

A Brazilian study conducted by Coutinho et al. (2), involving 21 patients with $S$. stercoralis infection, observed edema and infiltration of lamina propria by lymphocytes, plasma cells and eosinophils, in varying degrees, in addition to villous atrophy, crypt hyperplasia and criptite, which is consistent with cases presented in HUPES. Regarding clinical symptoms, both studies showed a predominance of abdominal pain, vomiting and diarrhea.

Kishimoto et al. ${ }^{(5)}$, after investigation of 25 patients infected with $S$. stercoralis, also presented, as predominant symptoms, the presence of vomiting, diarrhea, weight loss and abdominal pain. Moreover, Kishimoto found the presence of sepsis in $12 \%$ of cases. The degree of inflammation, atrophy/destruction of villi and infiltration of lamina propria was proportional to the severity of endoscopic findings, with $92 \%$ of subjects showing duodenal abnormalities at endoscopy. Among these, the predominant were mucosal edema, white villi, bleeding, exanthema and erosion of mucosa. These diverging results may be due to the fact that in this study $96 \%$ patients had some immunosuppression condition, mainly co-infection with HTLV-1, which is associated with hyperinfection by S. stercoralis. More severe disease would be responsible for exuberant clinical findings.

Kisimoto et al. ${ }^{(5)}$ also observed that $68 \%$ of 25 subjects studied had larvae of $S$. stercoralis in stool examination. Indeed, in 11 cases of HUPES, $80 \%$ of patients had stool sample examination positive for the agent found in biopsy, showing that intestinal parasitosis are a common neglected differential diagnosis. This finding again reinforces the need of stool examination for early investigations.

Due to the small sample of our study, it is not possible to make statistical inferences pointing to a possible strength of association between parasitic infections and duodenal symptoms, laboratory findings, endoscopic and histopathological findings. The work was underlied to some biases, which may have affected the final results. Some biases could not be minimized, as biopsies reports that may have issued false-negative results, reducing the final sample. Measurement biases like questionnaire mismatch and preparing the researchers were minimized whereas the data collection questionnaire was applied twice to suit the language presented in medical records and all researchers were trained together. However problems 
that surely involved final results were the poor quality of some records and the lack of data on some of them. A last review of biopsy specimens by a qualified pathologist avoided the inclusion of false-positives and allowed further characterization of findings.

This study differs from others in literature because have its starting point in general population, with analysis of all duodenal biopsies performed in last 14 years in the institution. There are few studies emphasizing relationship between duodenum and parasites. This subject is rarely discussed in literature, especially having the general population as the primary sample. Studies generally start from a population of immunosuppressed persons, especially HIV-positive patients. Another problem is that there is no standardization in researches, especially in regards to endoscopic and histopathological findings, and each paper describes them in a different way.

\section{CONCLUSION}

Parasites in duodenal biopsies corresponded to $1 \%$ of biopsies performed.

There are no endoscopic and histopathological findings said to be pathognomonic of parasitic duodenitis. Among the laboratory findings, anemic and malnourished patients with depletion of albumin are the majority.

There is no standardization for data collection, what would allow a better comparison between the existent results. This subject is rarely discussed in literature, with a possibly underestimated prevalence.

Santos RB, Fonseca Jr LE, Santana ATA, Silva CAC, Guedes JC. Perfil clínico, endoscópico e histopatológico de casos de duodenite parasitária diagnosticados por endoscopia digestiva alta. Arq Gastroenterol. 2011;48(4):225-30.

RESUMO - Contexto - Parasitas intestinais podem induzir alterações histopatológicas, que têm sido estudadas em subgrupos com diagnóstico firmado de parasitose. Não há estudo disponível com base mais ampla, sem diagnóstico prévio. Objetivo - Descrever os achados clínicos e histopatológicos de parasitoses diagnosticadas por biopsia em pacientes submetidos a endoscopia digestiva alta. Método - Laudos de biopsias realizadas de janeiro de 1995 a janeiro de 2009, no Complexo Hospitalar Professor Edgar Santos, hospital geral universitário localizado no nordeste brasileiro, foram revisados. Mil e dez laudos de biopsia duodenal foram revistos. Biopsias positivas para parasitas tiveram suas lâminas revisadas e fotografadas. Todos os blocos de biopsia selecionados como casos foram recuperados e revisados por experiente patologista. Dados clínicos, laboratoriais e endoscópicos foram coletados. Resultados - Onze biopsias mostraram parasitas, incluindo casos de Cryptosporidium sp. e Strongyloides stercoralis. Vômitos (91\%), dor abdominal (78\%), diarreia (78\%) e perda ponderal (78\%) foram sintomas comuns. Setenta e cinco por cento apresentaram alterações na mucosa duodenal à endoscopia, enquanto $25 \%$ não apresentaram modificações. Anemia e hipoalbuminemia foram importantes dados laboratoriais. Foi observada associação com infecção pelo HIV. Atrofia de vilosidades e epitélio reativo foram comuns nos casos de S. stercoralis. Conclusães - Nenhum achado endoscópico ou histopatológico foi patognomônico. Um por cento das biopsias duodenais por via endoscópica mostraram parasitas.

DESCRITORES - Enteropatias parasitárias. Duodenite. Biopsia. Endoscopia gastrointestinal.

\section{REFERENCES}

1. Arévalo SF, Cerrillo SG. Strongyloides stercoralis: hallazgos histopatológicos en mucosa duodenal 1999-2005. Rev Gastroenterol Peru. 2006;26:44-8.

2. Coutinho HB, Robalinho TI, Coutinho VB, Amorim AM, Almeida JR, Filho JT, King G, Jenkins D, Mahida Y, Sewell HF, Wakelin D. Immunocytochemistry of mucosal changes in patients infected with the intestinal nematode Strongyloides stercoralis. J Clin Pathol. 1996;49:717-20.

3. Genta RM, Chappell CL, White AC Jr, Kimball KT, Goodgame RW. Duodenal morphology and intensity of infection in AIDS-related intestinal cryptosporidiosis. Gastroenterology. 1993;105:1769-75.

4. Kearney DJ, Steuerwald M, Koch J, Cello JP. A prospective study of endoscopy in HIV-associated diarrhea. Am J Gastroenterol. 1999;94:596-602.

5. Kishimoto K, Hokama A, Hirata T, Ihama Y, Nakamoto M, Kinjo N, Kinjo F, Fujita J. Endoscopic and histopathological study on the duodenum of Strongyloides stercoralis hyperinfection. World J Gastroenterol. 2008;14: 1768-73.

6. Lumadue JA, Manabe YC, Moore RD, Belitsos PC, Sears CL, Clark DP. A clinicopathologic analysis of AIDS-related cryptosporidiosis. AIDS. 1998;12: 2459-66.

7. Macfarlane S, Dillon JF. Microbial biofilms in the human gastrointestinal tract. J Appl Microbiol. 2007;102:1187-96.
8. Manzione CR, Nadal SR, Calore EE, Manzione TS. Achados colonoscópicos e histológicos em doentes $\mathrm{HIV}^{+}$com diarréia crônica. Rev Bras Coloproctol. 2003;23:256-61.

9. Papp JP Jr, DeYoung BR, Fromkes JJ. Endoscopic appearance of cryptosporidial duodenitis. Am J Gastroenterol. 1996;91:2235-6.

10. Rivasi F, Pampiglione S, Boldorini R, Cardinale L. Histopathology of gastric and duodenal Strongyloides stercoralis locations in fifteen immunocompromised subjects. Arch Pathol Lab Med. 2006;130:1792-8.

11. Silva CV, Ferreira MS, Borges AS, Costa-Cruz JM. Intestinal parasitic infection in HIV/AIDS patients: experience at a teaching hospital in central Brazil. Scand J Infect Dis. 2005;37:211-5.

12. Thompson BF, Fry LC, Wells CD, Olmos M, Lee DH, Lazenby AJ, Mönkemüller KE. The spectrum of GI strongyloidiasis: an endoscopic-pathologic study. Gastrointest Endosc. 2004;59:906-10.

13. Weber R, Ledergerber B, Zbinden R, Altwegg M, Pfyffer GE, Spycher MA, Briner J, Kaiser L, Opravil M, Mevenberger C, Flepp M. Enteric infections and diarrhea in human immunodeficiency virus-infected persons: prospective community-based cohort study. Swiss HIV Cohort Study. Arch Intern Med. 1999;159:1473-80.

14. Zago-Gomes MP, Aikawa KF, Perazzio SF, Gonçalves CS, Pereira FE. Prevalence of intestinal nematodes in alcoholic patients. Rev Soc Bras Med Trop. 2002;35:571-4.

Received 4/4/2011 Accepted 19/5/2011 